\title{
0 papel e o mar: sobre estórias que não nos contam dos personagens negros da nossa história
}

\author{
The paper and the sea: stories that nobody tell us about the black characters of
} our history

Maíra Zenun de Oliveira - Universidade Federal de Goiás - mairazenun@yahoo.com.br

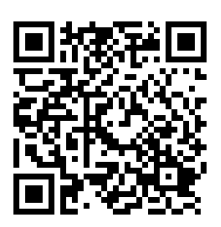

O presente artigo tem por finalidade discutir, a partir da narrativa da curta-metragem O Papel e o Mar (2008), de Luiz Antônio Pilar, a importância de obras cinematográficas que tragam para o protagonismo da História do Brasil estórias vividas por mulheres e homens negros brasileiros. Nesse sentido, a estória contada no filme em questão será apresentada ao longo deste texto em uma narrativa permeada por certa revisão bibliográfica a respeito da representação social e autorrepresentação do negro no cinema brasileiro.

E, assim como em uma estrutura fílmica, este artigo se desenvolve a partir das etapas de uma estória contada. Começo (apresentação dos personagens), meio (desenvolvimento do diálogo entre cinema, (auto) representação e negritude) e fim (conclusões sobre o que o filme sugere sobre o tema das relações étnico-raciais no Brasil).

A hipótese central para o desenvolvimento deste trabalho, portanto, é a de que a ausência de imagens de protagonismo negro no cinema, arte tida como expoente da contemporaneidade, pode dificultar a construção de um imaginário coletivo, nacional, que valorize a presença negra no processo de construção da História da sociedade brasileira. Como resultado, é importante ressaltar que, 
a partir desta análise sobre o filme O Papel e o Mar, foi possível perceber quanto Carolina de Jesus, escritora, e João Cândido Felisberto, o Almirante Negro, podem ser tomados como personagens importantes na (re)construção das representações da história da população negra brasileira no campo do cinema. Outra questão, não menos relevante, é o fato de que, embora seja crescente o número de obras que têm valorizado os protagonismos negros, ainda há uma enorme carência de produtos culturais que revelem, por meio do cinema, estórias coletivas e individuais, tanto de pessoas comuns quanto das lideranças negras brasileiras.

\section{COMEÇO}

O Papel e o Mar é um curta-metragem de aproximadamente 14 minutos de duração, dirigida por Luiz Antônio Pilar, que trata de um encontro fictício, porém histórico e representativo. O filme apresenta um diálogo imaginário entre Carolina e João, personagens que retratam Carolina Maria de Jesus, escritora, e João Cândido, o Almirante Negro - pessoas reais da história. Ele, figura central da Revolta da Chibata, movimento de resistência negra na Marinha Brasileira, interpretado pelo ator e diretor de cinema Zózimo Bulbul. Ela, catadora de lixo, mãe solteira e escritora, descoberta pela crítica literária entre as poucas possibilidades materiais disponibilizadas pela Favela do Canindé, na cidade de São Paulo, interpretada por Dirce Thomas.

No filme, as duas pessoas representadas são, de fato, figuras marcantes da historiografia negra brasileira. Os atores, Zózimo e Dirce, também fazem parte da história da arte negra brasileira. Em razão desse entrelaçamento de protagonismos, essa curta-metragem torna-se uma obra tão importante para o cinema negro nacional, por protagonizarem papéis que, nas mais diferentes mídias, são pouco atribuídos aos negros: de liderança política e de intelectualidade. Isso porque, segundo Muniz Sodré, em seu artigo Cor e civilização (2010), a mídia televisiva, por exemplo, torna a negra e o negro invisíveis e desnecessários. E essa invisibilidade, essa ausência de protagonismo e devir são uma das formas mais perversas de segregação e discriminação racial de que se faz uso no Brasil, desde o período colonial.

É dessa forma, portanto, que começa o filme de Luiz Antônio Pilar, do encontro inusitado entre Carolina e João. Uma paulista e um carioca. Uma escritora e um militar. Uma mulher da segunda metade do século XX e um homem do fim do século XIX, início do XX. Personagens aparentemente tão distantes e distintos e, no entanto, tão próximos e com tantas questões comuns a serem compartilhadas. Dois indivíduos negros brasileiros, protagonistas de relevância da história de construção das identidades negras nacionais.

No entanto, "De que adianta ter escrito uma das mais importantes páginas da história do país? [...] Eu fui banido de mim mesmo.", afirma o Almirante. A partir dessa fala, é possível perceber a reflexão apontada pelo filme sobre a ausência/presença de negras e negros nas páginas da história oficial, escritas pelo discurso hegemônico, por senhores brancos, detentores de privilégios políticos, econômicos, sociais e de educação.

Ao problematizarmos a pouca representação dos negros no cinema e na televisão brasileira, fixados sempre a papéis de pouca relevância hierárquica, trabalhos como o de Luiz Antônio Pilar merecem ser destacados e analisados. O diretor dessa curta é responsável por um novo - e recente - protagonismo midiático atribuído aos negros. Trata-se de uma questão de autonomização dos meios pela autorrepresentação social.

Coordenador e produtor executivo da Lapilar Produções Artísticas, que atua desde 2003 nas áreas de cinema, séries, programas de televisão etc., Luiz Antônio Pilar é um dos poucos cineastas que trabalham pela ampliação independente do Cinema Negro Brasileiro, apesar das barreiras impostas pelas mídias oficiais. Pilar desenvolve um tipo de produção que, levando em consideração a questão da autorrepresentação social do negro, só poderia vir de profissionais como ele, que tomaram para si a responsabilidade de contar outras versões do que se conhece sobre a História do Brasil. É possível dizer que há na obra desse autor uma escolha discursiva por autorreferendar suas próprias origens negras, elegendo a história desses ausentes para protagonizarem seus trabalhos cinematográficos.

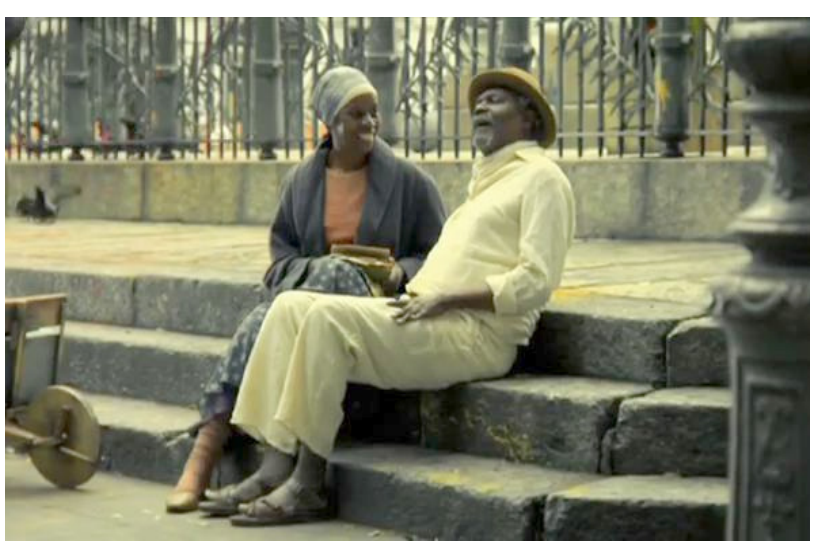

Figura 1 - Cena do filme O Papel e o Mar, de Luiz Antônio Pilar. Disponível em: <http://www. lapilar.com.br > Acesso em: 20 mai 2013. 


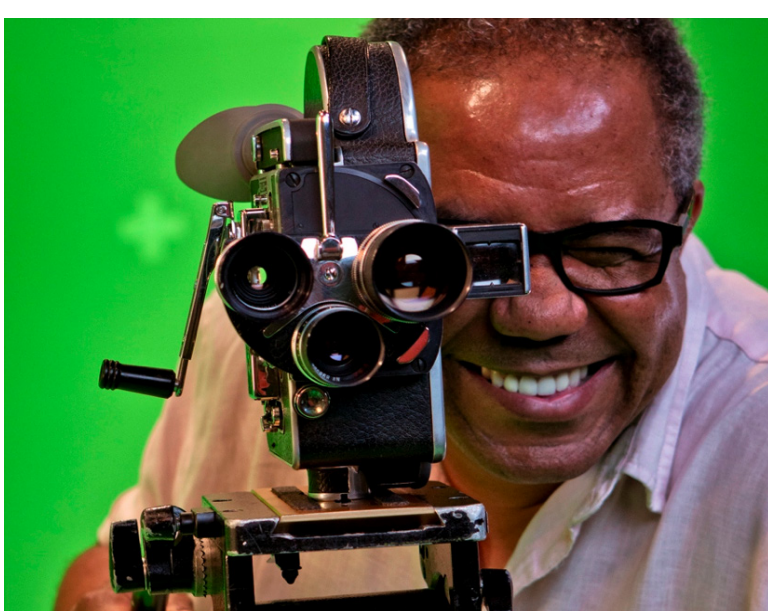

Figura 2 - Luiz Antônio Pilar, diretor do filme. Disponível em: $<$ http://www.revistaafro.com.br/ entrevistas/luiz-antonio-pilarnos-negros-somos-invisiveis-na-grande-midia> Acesso em: 25 mai 2013.

A questão da representatividade que aparece no texto de Muniz Sodré, não se resume, somente, à legitimidade na busca pelo olhar do outro ou ao respeito pelas especificidades culturais de cada grupo social. Daí a importância de se problematizar a questão da autorrepresentação, no intuito de discutir, além da legitimidade e da pertinência nas formas de representação das minorias, a questão da ordem do discurso. O problema da diversidade de percepções do mundo depende, cada vez mais, do acesso aos espaços de poder - hoje atribuídos aos meios de comunicação. E essa demanda jamais será suprida pela boa vontade daqueles que monopolizam os lugares de fala na sociedade contemporânea (DALCASTAGNÉ, 2007).

Luiz Antônio Pilar é negro, e como diretor de cinema negro, interessado em contar a história de mulheres e homens negros, quebra uma prática comum no campo das representações. Caso contrário, apenas o protagonismo das elites brancas continuaria sendo referendado. Se é que não é isso que acaba acontecendo. A falta de autorrepresentação restringe a História oficial à História das classes dominantes, dos homens brancos, das elites de poder. A possibilidade da autorrepresentação por aqueles que antes estavam excluídos e marginalizados atribui uma pluralidade de perspectivas que não será possível enquanto a História do Brasil continuar sendo contada apenas pelos estabelecidos, em detrimento dos outsiders (ELIAS, 2000).

Ao escolher contar uma estória inventada de um possível encontro entre Carolina e o Almirante, Pilar acaba por atribuir sentido a uma história sem sentido. Mas é preciso entender o porquê disso. Apesar da grande contribuição cultural, econômica e política que os africanos e seus descendentes desempenharam no processo de construção desta nação, eles ainda não são plenamente reconhecidos como sujeitos dessa história. A tendência é que a lacuna e o vazio continuem sendo perpetuados, enquanto não for relacionado às negras e aos negros deste país nenhum tipo de patrimônio cultural socialmente operativo.

Isso é demonstrado no filme quando o Almirante conta sua repentina mudança de status social, em função da sua participação e atuação política na Revolta da Chibata. Assim como veio a consagração imediata, também foi rápida a queda no esquecimento. João Cândido, apesar de ter contribuído para as lutas emancipatórias dos negros no país, não é reconhecido pelo Estado Brasileiro como tal, e, após a revolta, acabou sendo expulso da marinha mercante.

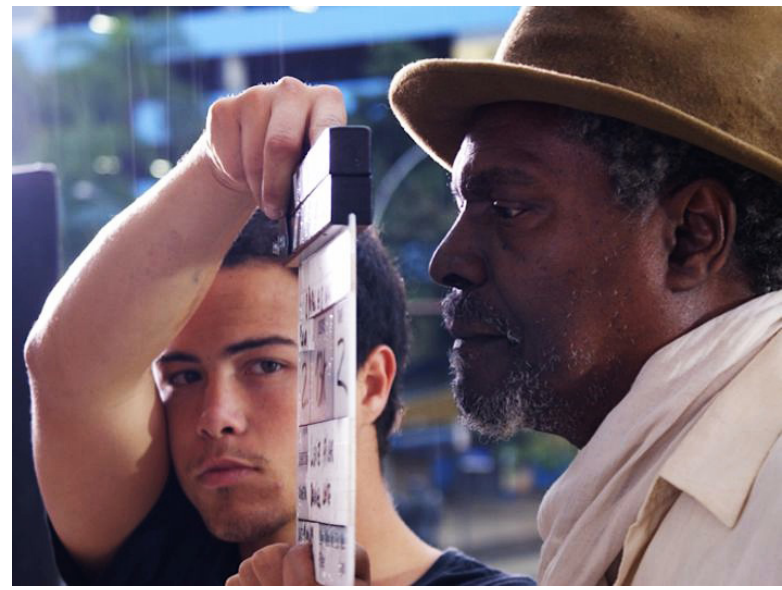

Figura 3 - Zózimo Bulbul interpretando o Almirante Negro. Disponível em: <http://www.lapilar.com.br > Acesso em: 20 mai 2013.

Fato é que vivemos na Era da Informação. O poder está na possibilidade de construir conhecimento através dos meios de comunicação. Televisão, cinema, internet: são todas formas de comunicar, legitimar e perpetuar. $\mathrm{O}$ papel da mídia é, portanto, muito importante, e por isso é necessário mostrar como a negra e o negro vivem e viveram no Brasil durante todos esses anos, desde a chegada dos africanos escravizados. Mostrar suas lutas e como essas pessoas foram importantes para a história do país é, hoje, uma necessidade. Na história do Brasil, temos escritores negras e negros, cantores negras e negros, artistas negras e negros... um universo inteiro de personalidades que tiveram suas estórias esquecidas ou nunca contadas. A partir de uma revisão sociocultural e histórica será possível (re)construir os processos de formação da sociedade brasileira. E somente esse processo permitirá uma real interferência no nosso padrão social, tão calcado no racismo e na exclusão.

Nesse sentido, a curta-metragem O papel e o Mar retrata a estória de dois personagens que falam das suas vidas e das suas invisibilidades, em relação ao passado e ao presente 
deste país. Eles encontram-se numa praça no Rio de Janeiro, a Praça XV - marco de grandes eventos sociais e políticos. É neste cenário que João Cândido avista Carolina mexendo no lixo, e surpreende-se ao notar que ela dá mais valor aos papéis que encontra do que às latinhas, que possivelmente Ihe trariam mais dinheiro. É nesse momento que ele se dirige a ela e fala da importância de recolher "um lixo nobre", como as latinhas. Mas ela logo afirma que o mais importante é (re)colher papéis, porque os melhores momentos da sua vida foram quando ela estava na escola. Além disso, Carolina conta a João que o papel tem mais valor, pois eles contam estórias. É a partir desse momento que se inicia um diálogo entre os dois. Um diálogo sobre a ausência e o esquecimento.

\section{MeIO}

Apresentados os personagens, são as suas angústias que tomam conta da narrativa. O Almirante é quem começa a contar um pouco de sua trajetória à Carolina, que também Ihe conta fatos de sua vida. Rapidamente, podemos reconhecer nesse diálogo a realidade dos tristes estereótipos atribuídos aos negros pela mídia hegemônica. Durante a conversa, eles também comentam o fato de estarem na situação de moradores/trabalhadores de rua, o que demonstra o lugar onde geralmente negras e negros empobrecidos vão parar, despejados na favela e na miséria da marginalização forçada.

Ele menciona a ela que já foi uma pessoa muito respeitável, líder de uma importante revolta no início do século XX. João Cândido era conhecido como O Almirante Negro, responsável por acabar com os açoites de chibata impostos aos marinheiros negros que cometessem qualquer ato de desobediência. As falas reproduzidas pela personagem do Almirante demonstram uma terrível amargura diante do que aconteceu após o episódio da Chibata. Como João tinha sido marinheiro no passado e liderado essa revolta, de cuja participação tanto se orgulhava, sentia muita tristeza pelo fato de não ter ganhado nenhum tipo de reconhecimento nos capítulos da história oficial do país.

O diálogo entre os dois protagonistas começa a ficar cada vez mais intenso, e é muito importante para o filme o momento em que João fala que o mar é sua vida e que não ganhou nenhum reconhecimento por tudo que fez. É nesse momento que Carolina sai para ver o mar e fala um pouco de sua vida, que está escrita em um diário. Esse diário, que ela guarda, retrata a sua vida na favela, lugar que ela entende como o de despejo da humanidade.
Importante perceber que o enredo da curta desenvolve-se a partir de elementos significativos da vida dessas duas personagens, como fica explicitado no título da obra: $O$ Papel e o Mar. O papel é onde Carolina registra e conta estórias, onde dá forma as suas experiências. E o mar é o ambiente que compõe o cenário, significado e ritmo da vida do marinheiro João Cândido. O que está demonstrado é que, a partir de uma interação ora apática, ora simpática entre esses personagens-elementos, do papel e do mar, João e Carolina distraem-se, dialogam e entregam-se às especificidades de suas vivências.

Na história de João, podemos ver a luta de classes que se estabeleceu entre negros e brancos no Brasil. Sua narrativa apresenta, em vários momentos, o menosprezo de indivíduos brancos em relação aos indivíduos negros. Mesmo quando o negro está tentando (re)escrever a história da sociedade brasileira, mesmo quando o protagonismo negro se dá pela luta de classes, mesmo assim a invisibilidade persevera. Este argumento propõe reflexões interessantes sobre questões específicas, como: será que se João fosse branco, ele teria sofrido tanta desconsideração durante a sua vida? Será que a forma com a qual ele foi reprimido não teria sido mais leve e piedosa se ele fosse branco? Será que a história que ele teria para contar não seria outra, se ele fosse branco?

Como Muniz Sodré aborda em seu texto Cor e civilização, o indivíduo negro precisa deixar de ser visto como "coisa", como algo que vive em meio aos brancos, que, por sua vez, são a população verdadeiramente reconhecida e legitimada pelo Estado Brasileiro. Fato é que, no Brasil, ainda hoje, as evidências de exclusão da população negra são estatísticas, possíveis de serem lidas nos índices de inserção dos negros na educação superior pública, no mercado de trabalho e nos espaços de representação midiáticos. Tanto que, a maior vítima do genocídio policial no Brasil é a juventude negra, consequência da marginalização a que estão relegados esses indivíduos.

De certa forma, podemos perceber que, no filme $O$ Papel e o Mar, há um enraizamento de estereótipos típicos atribuídos aos negros, como aquele grupo social que sempre acaba na miséria, ignorado. Mesmo que tenha feito qualquer coisa de útil para a sociedade, as representações usuais da população negra brasileira fazem parecer que não se trata de indivíduos dignos de reconhecimento, simplesmente pela cor da pele. Para o senso comum, essa característica é o fator preponderante que os coloca numa posição inferior na sociedade. No entanto, em determinado momento do filme, João Cândido fala algo memorável: sua história não poderá ser apagada porque ela é contada sob letras vivas da sociedade brasileira. 
O que ele quer dizer é que, embora negras e negros deste país tenham sido subjugados a posições inferiores da hierarquia social, esta é uma parte da história que jamais poderá ser apagada e esquecida. Por mais que se tente, ninguém pode apagá-la. A Revolta da Chibata e o Quarto de despejo (primeiro livro de Carolina de Jesus) já existem, são reais. A curta O Papel e o Mar é exemplo disso. Como o próprio João diz a Carolina: mesmo que rasguem as folhas, o que escrevemos permanece escrito na história. Existiu e existem até hoje muitos Joãos e muitas tantas Carolinas. Quantos, como eles, não enfrentaram o preconceito racial, o preconceito por ser mulher, o preconceito por escrever, numa época em que ninguém via o indivíduo negro como gente/agente na sociedade brasileira? Carolina, moradora da Favela do Canindé, catava papéis para aliviar suas mágoas e aflições. A escrita torna-se uma forma de denunciar a realidade, para Carolina. Quando querem se desfazer dos papéis, jogam no lixo; quando querem se desfazer das pessoas, jogam na favela, ela diz. Assim, Carolina expressa e entende as agruras da vida de exclusão a que foi submetida.

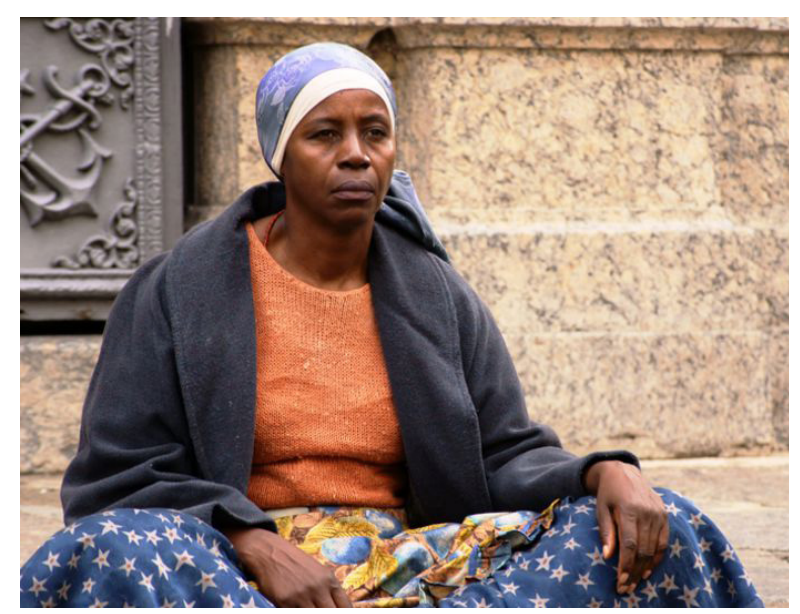

Figura 4 - Dirce Thomas interpretando Carolina de Jesus. Disponível em: <http://www.lapilar.com.br> Acesso em: 20 mai 2013.

Fato é que o indivíduo homem-branco tem suas ideias e discursos preservados pela doutrina eurocêntrica, em que o negro está entre nós, porém não é um de nós (SHOHAT e STAM, 2006, p. 45). Trata-se de uma parcela da população que continua sendo tratada como algo que deve ser mantido a distância, e sem relevância. Por isso, grandes escritores negros e negras de tamanho talento, tantas atrizes e atores negros, tantos artistas de várias áreas de produção não estão reconhecidos na cultura canônica, meramente pelo tom de pele que exibem e pela cultura que representam. Não se pode deixar de mencionar que a população brasileira possui (grande) parcela de negritude. Independentemente do multiculturalismo e da miscigenação que definem esta sociedade. E que não se trata apenas da melanina, presente na formação fenotípica de boa parte da população brasileira. A negritude brasileira está entranhada em muitos aspectos da sociedade e, especialmente, nas manifestações da cultural nacional. É inegável a influência negra em danças, como samba, maracatu, jongo ou afonjá. A difusão da capoeira, as influências religiosas do candomblé, as particularidades da nossa culinária. São tantos os elementos que os africanos trouxeram para a sociedade brasileira, que é inegável atentar para o fato de que, da história oficial que se conta, ou se apagou alguma coisa, ou de fato falta contar certas evidências e episódios.

Ocorre que a sociedade brasileira, de um modo geral, não aceita ou não conhece as interpretações afro-brasileiras de formação desta realidade. E é por isso que, após 126 anos de abolição da escravidão, a prática do racismo ainda está tão viva no inconsciente e nas práticas coletivas da população. Essa é a lacuna da história que faz com que o papel da mulher negra e do homem negro seja, ainda, tão estereotipado. As visões que são passadas nas redes de comunicação, na maior parte das vezes, mantêm-se fincadas na xenofobia, no exotismo e na subjugação, privilegiando apenas um lado dessa história. No caso, o lado branco, europeu e masculino.

Qual é o eco das ações dessas duas personagens na sociedade contemporânea neste cenário "futuro", que aparece de forma desconcertante como pano de fundo para João e Carolina? Inegável que os espaços que conferem voz e poder na sociedade atual parecem já ter dono. E, como ressalta Carolina, negras e negros brasileiros são insistentemente retirados de cena e jogados, como o lixo que ela cata, para os guetos da história.

Nesta discussão, é importante citar o artigo de Antônia Aparecida Quintão, A imagem das mulheres negras na televisão brasileira (2004), que discute o fato de as negras continuarem ausentes dos espaços midiáticos de poder. Para a autora, trata-se de uma categoria que, além de não compor os altos cargos administrativos, ainda está sujeita a outras formas de exclusão. E, enfatizando a questão da mulher negra nesse contexto, a exclusão, segundo Quintão (2004), é ainda mais latente.

O racismo aliado ao sexismo tem sido um dos principais obstáculos para que a mulher negra possa ter a sua cidadania assegurada, pois observamos que mesmo entre os negros, as diferenças de renda entre homens e mulheres são mais significativas que entre os demais grupos raciais. (QUINTÃO, 2004, p.55).

No filme, é visível que, no início, Carolina reage de forma agressiva à primeira abordagem do Almirante. Sua vida 
ensinou-Ihe que, na correlação de forças entre mulheres e homens, há uma enorme defasagem. Foi sobre a mulher negra que recaiu o grande peso de todas as heranças negativas deixadas pelo sistema escravocrata-colonial (HOOKS, 2000). Historicamente, há uma valorização da superioridade masculina, fortemente demarcada pelo patriarcalismo institucional. À mulher negra, de todo esse processo, restou a degradação e a subordinação percebidas nos obstáculos de gênero, enfrentados até os dias de hoje.

Somente depois de perceber que ela e João Cândido pertencem à mesma categoria marginalizada da sociedade e que o senhor negro aproxima-se na intenção de somar experiências, que Carolina desarma-se e admite a possibilidade de diálogo entre ambos. Ao se abrir para o marinheiro, Carolina fala que gosta de juntar papéis, que se sente importante fazendo isso. E acaba por estabelecer um paralelo entre seu trabalho e o que os governantes fazem quando isolam as pessoas em favelas como papéis inúteis, jogados fora, porque não servem para mais nada. Percebendo a abertura da moça, João também conta que muitas pessoas não queriam que ele fosse parte da história da Revolta da Chibata.

Perceba, a curta transforma-se numa dupla declaração de mágoas e acertos. De vitórias e derrotas. De lágrimas e resistência. Assistir ao O Papel e o Mar com a atenção voltada para o que diz o texto escrito por Muniz Sodré (2010) possibilita perceber que há uma íntima relação entre o que o autor discute e o que é mostrado no filme, como, por exemplo, o fato de o Brasil ser um país de uma maioria negra, totalmente desprivilegiada, mostrada como uma categoria sem sucesso.

Contudo, viver na Era da Informação traz novas opções de luta contra o racismo, tanto que esse valor cultural pode, e deve, ser modificado pelos meios de comunicação, que são os grandes responsáveis pela depreciação atual da imagem da população negra. No vídeo, as personagens sofrem do mesmo distanciamento que a sociedade brasileira impõe aos negros, tema tratado por Sodré em Cor e civilização. O outro (negro) é, constantemente, trazido para perto, mas sem realmente deixar de ser marginalizado como tal. É reconhecido como um qualquer, sendo então discriminado de maneira política e estética. Tal "distanciamento", retratado nas situações de discriminação, fica evidente quando percebemos que, não importando a notoriedade de suas experiências, João Cândido - Almirante - e Carolina - escritora - tornam-se moradores/trabalhadores da rua, em decorrência da segregação étnico-racial que vigora no Brasil. Portanto, entende-se que o negro no Brasil é um ser marginalizado da sociedade, mas faz parte dela, sem, no entanto, pertencer a essa mesma sociedade.
Assim como no filme, os textos de Quintão (2004) e Sodré (2010), mencionados ao longo do artigo, demonstram a forma como ocorre a regressão da imagem do negro em diferentes papéis: seja na vida real, como no caso do Almirante Negro, seja nos filmes e telenovelas, em que negras e negros estão quase sempre relegados a papéis subalternos.

Na curta, a construção do personagem de João Cândido se faz a partir do herói esquecido. Ele, que participou e liderou a luta contra o abuso aos marinheiros, foi preso e agredido. Ele, que era senhor dos mares como marinheiro e que possuía uma história de glória, foi sublocado para a posição de "peixeiro". Ele identifica-se com o mar. Lugar onde viveu e dele sobreviveu. Lugar onde lutou. É no mar que a sua vida encontra local de ação. E o seu medo é de que a sua história se apague.

A personagem Carolina está baseada na escritora Carolina Maria de Jesus e representa a busca pela autonomia da mulher negra, que deseja contar a própria história. Ela, mulher e favelada, mãe solteira e catadora de lixo, transgride esse enclausuramento do estereótipo e escreve a sua história, como forma de tomar as rédeas da própria vida. Ela identifica-se com o papel, que é muito mais que um material, um lixo. Que é para ela a única forma de resistência.

Num dado momento do filme, Carolina comenta sobre o diário que tinha, mas que abandona em vários momentos da vida. A cena a seguir é inesquecível. João rasga a página do caderno de Carolina e a provoca dizendo que ninguém mais saberia a sua história. Imediatamente, ele risca com lápis a página em branco, a página seguinte à que foi rasgada, e mostra que, mesmo tentando ocultar os fatos, não é possível, pois restam indícios, personagens, memória. O rabisco de lápis expõe as marcas do que foi escrito na página anterior. No filme, o discurso apresentado é de que tanto ela quanto ele, ambos têm a obrigação de continuar contando para outros as suas histórias.

Vai, Carolina! Joga logo. Joga logo o papel escrito dentro da garrafinha vinda do estrangeiro no mar, para que um dia alguém a encontre e assim se perpetue essa estória. Esse grito por eternização é o grito de quem foi esquecido e luta por reconhecimento, de quem passou a vida inteira lutando por aquilo em que acreditava, e que, mesmo assim, as relações de poder impuseram a invisibilidade. 


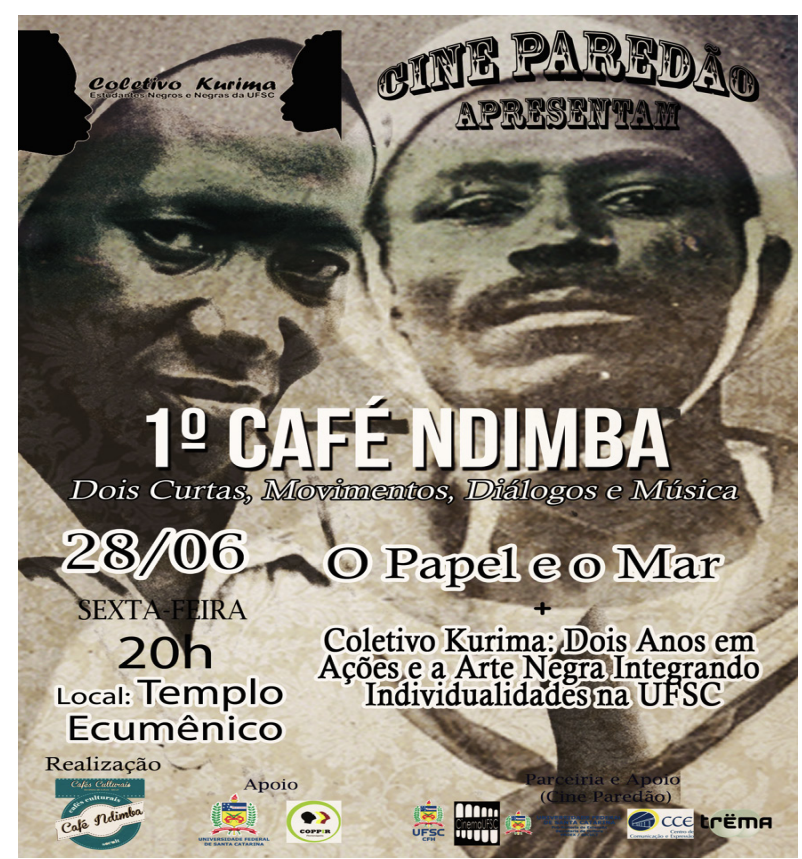

Figura 5 - Cartaz do $1^{\circ}$ Café Ndimba, onde foi exibido o filme. Disponível em: <http://noticias.ufsc.br/2013/06/coletivokurima-promove-cafe-ndimbanesta-sexta-feira-2> Acesso em: 27 mai 2013.

\section{FIM}

Para que se transforme essa visão que se tem do negro, como "figurante" de uma história que também é dele, pode-se aproveitar o período em que estamos vivendo em decorrência da supervalorização da informação. Tanto a televisão quanto o cinema têm grande poder discursivo sobre a sociedade. É necessário que haja uma mudança radical no tipo de imagem que está sendo veiculada a respeito dos personagens negros, assim como a quebra de paradigmas que se apresentam como obstáculos para a ativa participação das mulheres e homens negros na economia, cultura e sociedade como um todo.

Finalmente, o papel e o mar se unem na forma de uma história enviada ao mar em uma garrafa, para mostrar que a voz negra não é silenciável. Que as linhas escritas compõem a história e perpetuam-se na história. Na voz de João, de Carolina e de tantos outros negros e negras, uma outra história pode ser contada. Uma história de significados, contornos, caminhos e vivências outras. Estórias e histórias que já estão gravadas, presentificadas e que não podem ser subscritas. História de memória e civismo que já não se cala mais e que, pelo contrário, começa a alçar voo rumo à imensidão das possibilidades e identidades históricas.

O filme, portanto, gira sempre em torno de dois polos, entre os símbolos significativos dele e dela, abrangendo discussões que perpassam racialidades e gentrificações. Distantes na linearidade da história real do Brasil, são dois personagens bastante próximos no que se refere ao papel dos negros na forma oficial de exclusão e esquecimento. E, seguindo essa lógica, a narrativa do filme é construída a partir da dicotomia entre estas duas personagens - o papel e o mar - e traz a questão racial como ponto de convergência para o diálogo que se desenrola. Os protagonistas, Carolina e João Cândido, são negros e os dois são, à sua maneira, postos à margem de suas próprias histórias.

Apesar do período proposto, que na fala de João e Carolina data de 1958, o filme possui elementos claros da contemporaneidade, como veículos automotores do século XXI, pichações como intervenções em muros das ruas, barcos movidos a motor etc. Esses elementos podem ser vistos como uma incoerência temporal do filme, mas não exatamente de forma descuidada. Aponta, de certo modo, para a atemporalidade dessas personagens como constituintes de uma história que não é contada, mas está presente como as marcas das letras do caderno de Carolina. Uma página rasgada, que não se pode apagar em significado.

Concluindo, o filme termina com as duas personagens na beira do mar jogando uma página da História do Brasil no fundo do oceano, no intuito de manter viva a vida dessas personagens. Desse modo, é possível dizer que a arte é também uma mentira que diz a verdade. No caso do cinema, a questão da representação e da autorrepresentação produz narrativas variadas sobre o papel e a participação dos grupos marginalizados na história de uma sociedade. Mas como a pluralidade de interpretações pode afetar o nosso cotidiano? E como essas interpretações podem ajudar na formulação de novas formas de compreensão sobre o mundo em que vivemos?

Em virtude dos fatos mencionados, o filme procura tratar sobre pessoas negras que sofrem com o preconceito e o despejo humano. Elas vivem das ruas, guardando apenas a memória de suas lutas do passado. Vale ressaltar que, embora Carolina e João tenham sido esquecidos sob alguns aspectos da História do Brasil, é importante mencionar que na união do papel com o mar, a escrita de Carolina e a luta de João Cândido jamais foram em vão.

\section{ReFERÊNCIAS}

CARVALHO, Noel dos Santos. Contra a invisibilidade política e luta do negro por representação. In: ARAUJO, Joel Zito (org.). O negro na TV pública. Brasília: Fundação Cultural Palmares, 2010. 
DALCASTAGNÈ, Regina. A autorrepresentação de grupos marginalizados: tensões e estratégias na narrativa contemporânea. Revista Letras de Hoje. Porto Alegre, v. 42, n. 4, p. 18-31, dezembro 2007.

ELIAS, Norbert. Os estabelecidos e os outsiders: sociologia das relações de poder a partir de uma pequena comunidade. Rio de Janeiro: Jorge Zahar, 2000.

FERREIRA, Ceiça. Feminino negro na literatura e no cinema: os escritos e a história de Carolina Maria de Jesus. Anais... V Colóquio Mulheres em Letras, Belo Horizonte, 2013.

FERREIRA, Ceiça. Uma representação de si para o mundo: afetos e subjetividades no documentário performático. Razón y Palabra, n.82, março-maio /2013

HOOKS, Bell. Feminism theory: from de margin to center. Cambridge: South End Press Classics, 2000 (Chapter 1 Black Women: shaping feminist thought).

QUINTÃO, Antonia. Aparecida. Imagem das mulheres negras na televisão brasileira. In: CARRANÇA, Flávio; BORGES, Rosane da Silva. (orgs.) Espelho infiel: o negro no jornalismo brasileiro. São Paulo: Imprensa Oficial do Estado de São Paulo, 2004, p. 47-60.

SHOHAT, Ella e STAM, Robert. Crítica à imagem eurocêntrica. São Paulo: Cosac Naify, 2006.

SODRÉ, Muniz. Cor e civilização. In: ARAUJO, Joel Zito (org.). O negro na TV pública. Brasília: Fundação Cultural Palmares, 2010.

Recebido em: 28/02/2014

Aceito em: 18/09/2014 